\title{
El arte rupestre como producto complejo de procesos ideológicos y económicos: una propuesta de análisis
}

DÁNAE FIORE ${ }^{1}$

"Is simplicity best or simply the easiest?" 2

Martin Gore

\section{INTRODUCCIÓN}

El objetivo del presente trabajo es exponer algunas de las ideas que hemos elaborado y utilizado en la búsqueda de la definición de herramientas analíticas que nos permitan un abordaje del arte rupestre que de cuenta de la multiplicidad de sus dimensiones, y por lo tanto, de su existencia y su complejidad ${ }^{3}$. Intentaremos aproximarnos a la interrogante de "¿qué hace a un objeto obra de arte y qué permite diferenciarlo de los demás objetos?" (Delgado 1988: 34).

Dado que la complejidad del arte rupestre es un fenómeno vastamente caracterizado en la bibliografía especializada en el tema, y cuyos atributos dependen de los objetivos y del marco teórico del autor de cada investigación, consideramos necesario establecer desde un principio cuáles son los criterios o niveles que definen nuestra concepción de la misma, criterios que iremos desarrollando a lo largo del presente trabajo.

\footnotetext{
1 Museo Etnográfico, Universidad de Buenos Aires. Moreno 350 C.P. (1041). Buenos Aires. Argentina.

2 ¿Es la simplicidad mejor, o simplemente lo más fácil? (La traducción es nuestra).

3 Las ideas aquí presentadas han sido utilizadas en trabajos anteriores (FIORE 1993 a y b) como líneas téricas para la investigación de los procesos de producción del arte rupestre, pero hasta el momento no habian sido publicadas. El presente trabajo retoma una parte de dichas líneas, profundizando algunas consideraciones y agregando nuevos aspectos a esta perspectiva de análisis.
} 
Cuando analizamos las imágenes del arte rupestre de una sociedad, la característica dominante a primera vista es su composición plástica, es decir que su existencia se centra en la expresión a través de la imagen visual. Este primer nivel se encuentra absolutamente imbricado con el segundo, ya que dicha manifestación no puede desvincularse del contenido de lo que se expresa. El mismo, ya sea de naturaleza fantástica o naturalista se encuentra vinculado al dominio ideológico de la sociedad productora, de ahí que habitualmente se identifique de manera primordial o exclusiva al arte rupestre con la expresión ideológica de una sociedàd. A nuestro criterio, dichos contenidos ideológicos explícitos, que son los que intencionalmente se expresaron en las imágenes rupestres, no agotan el sentido de lo ideológico, dado que también existen ciertos contenidos ideoIógicos implícitos, que rigen, pautan y organizan la producción social del arte rupestre, y que pueden ser analizados a partir de ciertos indicadores arqueológicos.

Dichas pautas, por lo tanto, se encuentran asociadas con el proceso de trabajo implicado en la realización del arte rupestre, tercer nivel en el que se conjugan en la práctica las dos instancias anteriores con aquellos elementos destinados específicamente a materializar las imágenes, es decir, las herramientas, los pigmentos, el espacio seleccionado/disponible como soporte (Aschero 1988), las relaciones de producción, la fuerza de trabajo, etc.

Son estos tres niveles - la composición plástica de la imagen visual, los contenidos ideológicos implícitos y explícitos, y el proceso de trabajolos que caracterizan al arte rupestre en su complejidad y como producto social, actuando como condiciones que lo definen cualitativamente más allá de las formas y contenidos específicos que pueda manifestar en particular una determinada producción artística en un momento de la historia de una sociedad.

Nuestro interés radica además en que esta definición cualitativa del arte rupestre como producto social nos inste a una aproximación hacia dicha complejidad de manera no etnocéntrica. Esto implica, por una parte, evitar el uso del concepto hegemónico del "arte" occidental, es decir, el arte como producto de un genio individual y descontextualizado de su sociedad - sensu Delgado (1988), quien critica con amplios fundamentos esta postura-, alejándonos también de colocar a dicho arte como parámetro estilístico, estético o plástico mediante el cual se miden el resto de los productos artísticos.

Pero, por otra parte, nuestra postura implica evitar subsumir el significado de la palabra arte al concepto occidental recién expuesto, y poder 
conferirle otra clase de contenidos, ya que de lo contrario estaríamos obligados a abandonar la posibilidad de calificar de arte a toda producción plástica de sociedades no occidentales, o de sociedades del pasado. El sostener que el concepto de arte no es aplicable a otras sociedades con el objeto de no imponer contenidos de nuestras culturas occidentales a otras no occidentales (presente o pasadas), puede lograr un efecto absolutamente contrario, quitándole al "otro» la posibilidad de haber producido arte, es decir, puede volver por otro camino a una postura etnocéntrica.

Definidos entonces nuestros objetivos y puntos de partida, resta solo señalar que el desarrollo de nuestras consideraciones ha sido concebido desde una perspectiva arqueológica, a la que señalamos como adecuada para desentrañar el complejo proceso de producción del arte rupestre como producto de sociedades antiguas.

\section{EL ARTE RUPESTRE COMO PRODUCTO SOCIAL: UNA PERSPECTIVA DE ANÁLISIS}

En primer término, es importante destacar que nuestro análisis de toda producción social, incluyendo la del arte rupestre, se basa en la concepción de que a lo largo de su existencia, los hombres producen sus propias condiciones de vida tomando elementos de la naturaleza y transformándolos con el objeto de lograr distintos fines. A esta actividad caracteristica del género humano se la denomina proceso de trabajo (Bate 1981, Vargas Arenas 1986). Toda producción humana es siempre fruto de ese proceso, y tiene como resultado un determinado tipo de socialización de la naturaleza ${ }^{4}$.

Mediante este proceso, a lo largo de la historia de una sociedad se crean infinidad de productos sociales, entre los cuales encontramos al arte rupestre. De acuerdo con lo expuesto en la introducción, el uso del término arte puede conllevar distintas posturas teóricas (a veces contrapues-

\footnotetext{
4 La socialización de la naturaleza puede verificarse tanto en la dinámica del proceso de trabajo como en los restos materiales de dicho proceso. En el proceso de trabajo la verificación es sencilla: si observamos a un hombre confeccionando un hisopo con fibras vegetales veremos el proceso de transformación de la materia prima - perteneciente al reino de la naturaleza - en un artefacto - perteneciente al dominio de la culfura-. En los restos materiales resultantes de dicha actividad, el proceso de trabajo está implícito, y con él lo está también la socialización de la naturaleza. De hecho, toda evidencia arqueológica es reconocible por los trazos que en ella ha dejado el trabajo humano, trazos que permiten distinguirla de cualquier producto de la naturaleza. Por esta razón, puede decirse que los procesos de trabajo tienen una alta visibilidad arqueológica. (FIORE 1993 a: 24).
} 
tas), razón por la cual, debe utilizárselo con extrema precaución (para una discusión acerca de este punto, ver Llamazares (1986 b:26) y Fosati et. al. (1990:6) -entre otros-). Es por esta razón que conviene aclarar que, en este trabajo, cuando hacemos uso del término «arte", estamos haciendo alusión específica a lo que podemos denominar - sin ninguna otra connotación teórica- como "artes plásticas" o "artes visuales", dentro de las cuales incluímos al arte rupestre, por tratarse de un tipo más dentro del fenómeno de la producción de imágenes visuales.

Este producto social puede ser analizado mediante los diversos niveles ya mencionados, los cuales nos permiten, como primer paso, definirlo de manera amplia y general, sin aludir a contenidos específicos. Como un segundo e insoslayable paso es necesario analizar cuáles son las particularidades que caracterizan al arte rupestre en cada caso, acotándolo a un grupo social en un tiempo y un espacio determinados. (Este segundo paso será abordado en el acápite relativo a "estilo"). Esto implica que necesariamente cada caso de análisis requiere de ciertas técnicas de aproximación y/o relevamiento, así como de ciertos conceptos creados específicamente para su estudio, dado que dichos niveles se estructuran y dinamizan de manera particular de acuerdo a cada momento histórico.

Nuestra intención es entonces la de definir en este acápite algunos niveles que nos permitan realizar el primer paso, es decir, delimitar al arte rupestre como producto social distinguiéndolo de otros productos que las antiguas sociedades hayan generado a lo largo de su historia. Es en este sentido que consideramos a dichos niveles como amplios y generales, ya que pueden servirnos para identificar cualitativamente la existencia de dicho producto sin remitimos a una definición escencialista -inmutable y ahistórica- de qué es el arte.

Ahora bien, como ya hemos señalado, habitualmente se considera al arte como una instancia principalmente ideológica, mientras que, por ejemplo, la subsistencia es asignada a una instancia básicamente económica. Al respecto, hemos ya expresado en otro trabajo que «...el arte rupestre no es el único indicador arqueológico del que disponemos para analizar la ideología" (Fiore 1993 b: 1), remitiéndonos así a la posibilidad de analizar la instancia ideológica en cualquier otro producto social distinto al arte rupestre, como por ejemplo las pautas ideológicas irnplicitas en la explotación de recursos liticos o las estrategias de caza. En dicho trabajo hemos también sugerido que «...el arte rupestre no es únicamente indicador de la ideología, es también un indicador relevante para analizar otras instancias sociales, por ejemplo, la economía.» (ídem) 
Esta última perspectiva es, en parte, la que puede encontrarse sustentada en trabajos tales como los de Krapovickas (1961), Núñez Atencio (1976), Yacobaccio (1979), o Jochim (1985) al haber vinculado el arte rupestre de sus respectivas áreas de estudio con el tráfico caravanero de camélidos (en los tres primeros casos), o con procesos ambientales y demográficos, particularmente la explotación de un recurso ictícola como el salmón (en el últirno caso). En estos casos se trataría del establecirniento de relaciones entre las manifestaciones rupestres y las actividades de subsistencia que en ellas se encuentran representadas, o que demarcan o se asocian a una ruta determinada de desplazamiento de bienes y personas.

Pese a la interesante y fructífera postura asumida por estos autores, no es nuestro objetivo el plantear en este trabajo vinculaciones entre el arte rupestre y la instancia económica de otros productos sociales, es decir, al exterior del mismo (como en aquellos casos), sino que nuestro interés radica en marcar la dimensión económica propia del arte rupestre, al interior del mismo, originada en su propio proceso de producción.

En este sentido cabe señalar que en el arte rupestre puede advertirse una doble cualidad: la de representación simbólica de una realidad (representaciones de ideas, de sentimientos, de hechos, delimitaciones o demarcaciones territoriales, decoraciones de espacios, etc.), y la de realidad material en sí (involucrando entonces no solamente una referencia hacia la realidad "exterior" sino una existencia material propia, que implica un proceso de producción interno y específico al arte rupestre, es decir, una dimensión económica).

A nuestro criterio, son los trabajos de Leroi Gourhan (1976) y Aschero (1988), los que han marcado con mayor énfasis la existencia de esta dimensión económica del arte rupestre a la que hacemos referencia. En el primer caso, Leroi Gourhan (1976) explicita una serie de aspectos relativos a la identificación de una instancia económica particular y específica del arte rupestre, entre los que menciona el tiempo invertido en su realización, el rol del artista en la sociedad (su posible especialización en la labor de producción artística y la compensación económica requerida por la sociedad al posibilitar que ciertos individuos no participaran del proceso de producción de alimentos), y el valor material del arte rupestre como objeto de intercambio.

En el segundo caso, Aschero (1988) sostiene que en el análisis del arte rupestre pueden deslindarse, entre otros aspectos, el contexto de significación (constituído por el contexto funcional de ejecución y el contexto temático de la representación) y la secuencia de producción, mantenimiento y reciclado. De esta manera, puede decirse que el autor abarca 
en su perspectiva a la ideologia como nivel de análisis, el estilo como unidad de análisis, y los recursos naturales como tipo de evidencia vinculada con el arte rupestre, abriendo los márgenes de la identificación entre imágenes rupestres e ideología y ampliándolos hacia otras dimensiones.

Podemos afirmar entonces que en la postura que vincula de manera unívoca arte con ideología, (o, por ejemplo, subsistencia con economía), subyace una sólida identificación entre los productos sociales que son nuestros objetos de estudio y los niveles de análisis que utilizamos para analizarlos. Dicha identificación se basa en suponer la existencia de entidades o productos sociales exclusivamente políticos, económicos, ideológicos, etc., cuando éstos son en realidad niveles abstractos en los que descomponemos a aquellos con el objeto de analizarlos, aunque sin descuidar el hecho de que los mismos son siempre fruto de la interacción necesaria y simultánea entre todos estos niveles o instancias.

Esto podría hacernos suponer que la perspectiva planteada no nos permite realizar una diferenciación entre los distintos productos creados por el hombre, ya que en la producción de todos ellos intervienen las mismas instancias de la sociedad. Por el contrario, el reconocimiento de todas las instancias que interjuegan en la creación de un producto y la identificación de la manera en que las mismas se combinan, es precisamente el medio que posibilita una verdadera diferenciación entre los productos sociales, una diferenciación intrínseca a su existencia, ya que se enraiza en su propio proceso de producción, permitiéndonos aclarar la distinción entre los productos sociales que son objeto de nuestros estudios (el arte; la subsistencia; la tecnología) y los niveles de análisis que usamos para investigarlos (lo ideológico; lo económico; lo político).

Los productos sociales son, entonces, las entidades reales y concretas con las que nos enfrentamos, y cuya existencia pretendemos explicar, mientras que los niveles de análisis son las entidades abstractas mediante las cuales intentamos realizar dichas explicaciones ${ }^{5}$. En el gráfico 1 se representa esquemáticamente la diferencia entre productos sociales y niveles de análisis mediante dos "metáforas arqueológicas": la visión en planta para el primer caso, y la visión en perfil o corte para el segundo.

En la visión en planta (gráfico 1 a) se representan esquemáticamente algunos de los productos que son generados por una sociedad. La misma intenta graficar tanto la existencia de los "limites" de los productos socia-

5 Este punto ha sido tomado para un desarrollo más profundo y con implicancias más generales en otro trabajo (ÁLVAREZ y FIORE 1994 a). 

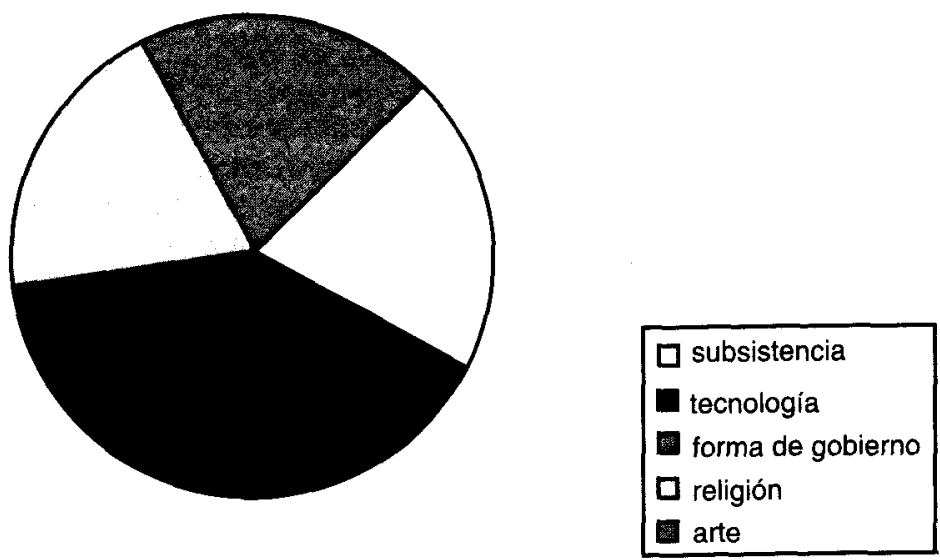

Gráfico ta. Visión en planta: productos sociales.

les como la existencia de una constante interacción entre los mismos. Los “límites" o «separaciones» entre productos sociales están generados por la propia identidad de cada producto, dada por sus condiciones particulares de existencia, que los definen y los caracterizan. Dichos límites son demarcados analíticamente, pero se sustentan en la propia materialidad real de los productos: un artefacto es distinguible de otro, así como también es posible diferenciarlo de una imagen de arte rupestre.

Pero como decíamos anteriormente, la especificidad de un proceso de producción -en este caso del arte rupestre - no implica un aislamiento del resto de los procesos de trabajo que se generan en una sociedad. Los contenidos expresados en las imágenes se remiten habitualmente a referentes fuera del ámbito de lo artístico, asi como los conceptos y conocimientos que pautan la producción de las representaciones rupestres no son exclusivos de las mismas, sino que intervienen en la generación de otros productos, y algunos de los propios procesos de producción que involucra el arte rupestre pueden ser desplegados también con otros fines.

Tal es el caso, por ejemplo, de la cadena operativa de producción de artefactos utilizados para realizar grabados rupestres. Dicha cadena posiblemente haya estado relacionada con objetivos más amplios que la exclusiva realización de artefactos para confeccionar imágenes, incluyendo la producción de artefactos para otras actividades, tales como la cacería, el procesamiento de cueros, la manufactura cerámica, etc. Sin embargo, la propia dinámica de la cadena, por ejemplo en la etapa de uso de los artefactos, en la que se los emplea para realizar los grabados, la vincula con 
la cadena operativa de producción de las imágenes, y le brinda al proceso la especificidad antes mencionada, permitiendo demarcar la identidad o particularidad del producto - en este caso el arte rupestre-, es decir, definir sus «límites».

En la visión en perfil o corte (gráfico 1 b) se representan algunos de los niveles de análisis que discriminamos con la intención de estudiar a los productos sociales en mayor profundidad, intentando acceder a la complejidad de su estructuración. A diferencia de los productos sociales, los niveles de análisis son disociables sólo analíticamente, con el objeto de focalizar nuestro estudio en alguno de ellos en particular, dado que no existen "separadamente" ni poseen «límites" propios, por tratarse de entidades abstractas.

$$
\text { Producto social }=\text { arte rupestre }
$$

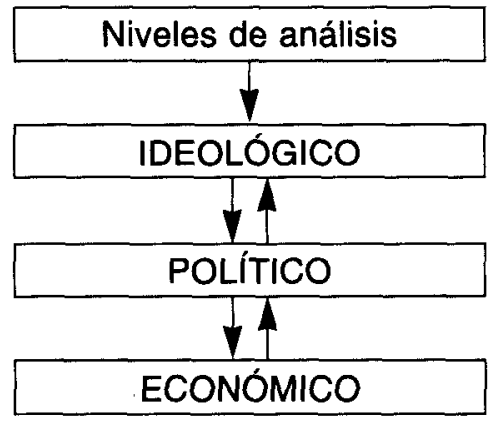

Gráfico 1b. Visión en perfil o corte: algunos de los niveles de análisis discriminables en un producto social.

Esto implica que en la definición de cualquier producto social, sea el arte, la subsistencia, la tecnologia, etc., es imprescindible reconocer dos niveles. Por una parte, toda producción social involucra a la totalidad de las instancias de la sociedad, ya que las mismas participan en conjunto de todo proceso de producción, por ser indisociables y simultáneas (sensu García Canclini 1986) ${ }^{6}$. Por esta razón, toda producción social puede ser

6 GARCIA CANCLINI (1986: 78) ha introducido oportunamente en la discusión teórica la atribución de “indisociables y simultáneas" a la estructura y superestructura de una formación econó. mico social. Un análisis pormenorizado de ambas categorías en lo respectivo al arte rupestre ha sido uno de los ejes básicos de nuestra Tesis de Licenciatura (FIORE 1993 a), razón por la cual no constituye un objetivo del presente trabajo. Sin embargo, retomamos las nociones de indisociabilidad y simultaneidad dado que consideramos que resultan también válidas para la caracterización de las vinculaciones entre las instancias sociales que intervienen en la generación de todo producto. 
abordada mediante todos los niveles de análisis disponibles de acuerdo al marco teórico desde el cual se define el problema.

Por otra parte, la especificidad de una producción social reside en la manera en que dichas instancias se combinan para darle origen, lo cual distingue y define a cada producción social en particular. En el caso del arte rupestre, consideramos que por la naturaleza de su calidad expresiva a través de la producción de imágenes y su posterior «uso», la interacción entre morfologia, contenidos, composición y técnicas hace de éste un producto social cualitativamente distinguible, aunque con especificidades históricas de acuerdo al tiempo, espacio y grupo social que lo haya producido.

\section{EL ARTE RUPESTRE COMO PRODUCTO SOCIAL: NIVELES DE ANÁLISIS PARA SU APROXIMACIÓN CUALITATIVA}

Nuestra perspectiva asume entonces que así como la subsistencia puede ser reconocida como una instancia particular de cualquier sociedad, sin importar que esté sustentada en la cacería, en la agricultura, o en la pesca, el arte posee una especificidad que permite reconocerlo y definirlo - de manera amplia y general- más allá de la tecnología mediante la cual haya sido producido, de la significación de los mensajes que emita, o del rol social de los «artistas" que lo hayan creado.

Sin entrar en la polémica discusión acerca de las evidencias sobre el inicio de la producción artística y sus limites cronológicos, podemos plantear que con la creación del arte parietal el hombre gestó un cambio cualitativo con respecto a toda producción cultural previa. Dicho cambio se constituyó por la expresión de ciertos contenidos ideológicos a través de diferentes modalidades tecnológicas. A partir de entonces, el hombre pasó de producir solamente sus condiciones de vida a producir, además, la expresión de sus reflexiones acerca de las mismas ${ }^{7}$ (Fiore 1993 a: 28). De esta manera, el arte rupestre se convirtió en el vehículo de por lo menos una parte de la ideología de las sociedades que lo producían, ex-

7 Cuando nos referimos a la "expresión de reflexiones sobre las condiciones de vida" segujmos a Aschero (1988), quien concibe a los referentes del arte rupestre como elementos tanto materiales como imaginarios que se vinculan con el entorno natural y cultural del grupo productor. De esta manera, no excluimos las construcciones míticas, fantásticas, etc., dado que consideramos que las mismas son siempre formuladas desde el contexto de las condiciones materiales de vida que una sociedad atraviesa en un momento determinado de su historia, aunque, obviamente no podamos, en muchos casos, dar cuenta de ellas arqueológicamente. 
presando ciertos contenidos o significados mediante la composición de imágenes visuales.

Por lo tanto, el arte rupestre, desde sus inicios, se caracterizó por la comunicación de contenidos (Conkey 1984, Boschín y Llamazares 1992, Aschero 1993, entre otros). Su creación gestó la existencia de un producto social que genera estímulos vinculados con lo sensorial a través de la composición plástica de la imagen visual (Fiore 1993 a). Este es el primer nivel que, a nuestro entender, caracteriza cualitativamente al arte, y nos permite definirlo, como producto social universalmente.

Ahora bien, en la comunicación de dichos contenidos pueden deslindarse dos aspectos. El primer aspecto está vinculado con la expresión intencional de un mensaje, con uno o varios significados determinado, a los que es sumamente difícil acceder arqueológicamente. Denominamos a este nivel como contenidos ideológicos explícitos o intencionales. Los mismos están constituidos por los contenidos o significados de los mensajes brindados en las imágenes, ya que entendemos que toda producción artística brinda un mensaje intencionalmente, aunque el objetivo de éste sea no brindar ninguna reflexión sobre la realidad (no referirse a la realidad es dar un mensaje sobre un determinado tipo de relación con la misma).

Esto no debería inducirnos a pensar que los contenidos ideológicos explicitos son directamente observables a partir de los motivos naturalistas (un bisonte, una huella de guanaco, un motivo antropomorfo, un boomerang) cuyos referentes son conocidos. Si bien los referentes de los motivos, es decir las entidades - materiales o ideales- a las que los motivos representan constituyen una porción fundamental de su significado, no son su significado. El significado de dichos motivos proviene no solamente del conocimiento contextual de cuáles son los referentes, sino de la información que, mediante las imágenes, pudo decodificarse en el pasado. Conocer qué es lo que está representado - un animal, por ejemplo- no significa conocer la interpretación de su significado - podría ser peligro, podría ser presa, podría ser fertilidad. De ahí la dificultad en la búsqueda de su significado.

Este aspecto es el que ha llevado a la identificación habitual de la producción artística con la instancia ideológica de una sociedad, principalmente cuando es ágrafa, ya que muchos otros tipos de productos sociales no conllevan la expresión intencional de significados, razón por la cual se trata de una cualidad prácticamente exclusiva del arte. Si bien reconocemos esta particularidad del producto artístico como aquel que emite contenidos ideológicos explícitos, consideramos que cerrar el análisis en este punto resulta ciertamente reduccionista, dado que se descartan otros aspectos y niveles que develan el verdadero valor de la complejidad del arte. 
En este sentido, Conkey ya ha expresado que:

«... la relevancia de los estudios del arte Paleolítico para la prehistoria, para la arqueología de los cazadores recolectores y para la comprensión del comportamiento simbólico humano tiene más dimensiones que la lectura del significado del arte Paleolítico." (1984: 254 el subrayado y la traducción son nuestros).

Por una parte, la asociación de lo artístico exclusivamente con lo ideológico se basa en un sobredimensionamiento de los contenidos del mensaje o del significado, por encima de otros aspectos que, tal como veremos más adelante, también constituyen al producto artístico. Por otra parte, dicha asociación se sustenta en la reducción de lo ideológico al plano de lo simbólico. Lo simbólico, aquello que abstrae una realidad mediante una imagen creada para representarla, es una parte importante de lo ideológico, pero no agota su contenido, ya que este incluye también un segundo aspecto.

Este segundo aspecto del nivel ideológico está vinculado con los conceptos necesarios (Aschero 1988: 52, Boschín y Llamazares 1992: 28) para llevar a cabo el proceso de producción del arte, tales como las pautas de uso de los espacios propicios para realizar las imágenes (Shaafsma 1985), los conocimientos necesarios para emplear y/o crear las distintas técnicas, la asignación de roles en la división del trabajo de producción artística (Leroi Gourhan 1976), el valor de la obra terminada (ídem) o la estructuración de un sistema que subyace al "diseño" del arte rupestre, el cual organiza las formas de composición de la imagen.

A este aspecto lo denominamos como contenidos ideológicos implícitos, muchos de los cuales pueden ser inferidos a partir del análisis del producto social bajo estudio. La facilidad o dificultad de acceso e ingreso a un sitio en el que se realizará arte rupestre, sus condiciones de protección de las personas productoras y observadoras de las representaciones, y de exposición u ocultamiento de las imágenes, la orientación del sitio, sus posibilidades de iluminación natural, la selección de ciertas paredes o ciertos sectores del soporte, el uso de determinadas formas de la microtopografia del soporte, la selección de determinados pigmentos y determinados diluyentes y aditivos para realizar las pinturas, la asociación (o falta de asociación) de colores con motivos (Fiore 1993 a), son algunos de los indicadores que pueden tomarse en cuenta como variables de análisis a partir de las cuales inferir estos contenidos ideológicos implicitos en su producción.

Algunos de estos indicadores, como la asociación de motivos entre sí en el soporte o la asociación de ciertos motivos con ciertos colores muy posiblemente hayan contribuido a la conformación del significado de las 
imágenes, razón por la que podrían considerarse dentro de los contenidos ideológicos explicitos. Sin embargo, la observación presente de estas imágenes producidas y "utilizadas" en el pasado sólo nos permite -cuando es posible- establecer patrones vinculados al sisterna visual subyacente a la construcción de las imágenes. Por esta razón, pese a su naturaleza expresiva, consideramos a este tipo de indicadores dentro de los contenidos ideológicos explicitos, ya que también nos brindan información sobre las pautas de diseño de los antiguos sistemas visuales.

Pese a la habitual falta de reconocimiento como tales, las pautas en las que se basan las decisiones implicitas en toda actividad humana son precisamente esos contenidos ideológicos, que están presentes, además de en la creación del arte, en cada producción social, como por ejemplo en la de artefactos cerámicos o en las actividades de recolección de vegetales.

Ambos aspectos -contenidos ideológicos explicitos e implícitosconstituyen entonces la dimensión ideológica del arte, conformando el segundo nivel que define cualitativamente al arte como un producto social.

Resta entonces referirnos al nivel relativo a la materialización de las imágenes, a la expresión real y concreta de los contenidos simbólicos a través de ciertas conductas materiales específicas, es decir, al proceso de trabajo en el arte rupestre. Dicho proceso tiene una especificidad propia, dada por la manera particular de concatenación entre el uso de determinadas fuerzas productivas ${ }^{8} \mathrm{y}$ el establecimiento de ciertas relaciones sociales de producción ${ }^{9}$.

Es por ello que consideramos adecuado el concebir al arte como un producto del trabajo hurnano, no solamente en el sentido en el que lo hemos definido (como el proceso de transformación de un objeto de la naturaleza en un artefacto, ecofacto o rasgo), sino también, y de rnanera imprescindible, en el sentido de que deben ser el producto de una labor que ocupa por lo menos parte del tiempo de las personas que la realizan.

Esto implica un ejercicio cotidiano (no necesariamente diario) de por lo menos parte del proceso de producción del arte, a partir del cual, mediante una práctica que incluye el mecanismo de ensayo y error, los productores

a Denominamos fuerzas productivas al conjunto de medios de producción, objetos de trabajo y fuerza de trabajo que dispone una sociedad en un momento determinado de su historia. (GODELIER 1976).

9 Concebimos a las relaciones sociales de producción como aquellas establecidas entre los hombres y los medios de producción, los hombres y los objetos de trabajo, y los hombres entre sí de acuerdo con la disponibilidad que una sociedad tiene de los mismos en un espacio y un tiempo determinados. (GODELIER 1976). 
crean y recrean tanto las técnicas de ejecución como las imágenes (en este caso visuales), y también su propia creatividad. Este es, entonces, el tercer nive/ que completa nuestra concepción del arte como producto social.

Integrando ahora los tres niveles ya delineados, puede decirse que la cornplejidad del arte rupestre está dada por el despliegue de estimulos sensoriales mediante la construcción de imágenes visuales (nivel l) en las que se han expresado significados o contenidos de manera explicita (nivel 2 a). Dichas imágenes exhíben una distribución espacial en el soporte que se estructura mediante una serie de operaciones de composición, que, junto con los patrones de uso del espacio como sitio y como soporte, y los conocimientos técnicos en cuanto a pinturas y grabados y a los artefactos involucrados en uno y otro caso, constituyen los contenidos de ideológicos implícitos (nivel 2 b) en la organización del proceso de producción material del arte rupestre (nivel 3).

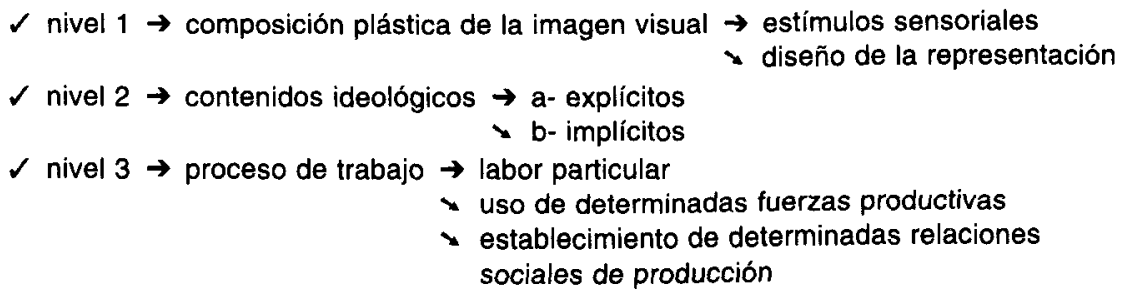

Gráfico 2. Niveles de análisis del arte como producto social

Retomando la doble cualidad del arte rupestre mencionada en el punto anterior, resulta posible ahora realizar una observación más profunda sobre la misma. Si el arte es simultáneamente realidad y representación de la realidad, el establecimiento de relaciones sociales involucradas en su producción no es solamente una instancia de su existencia material, sino que dichas relaciones pueden ser también un tema o un contenido a ser representado.

Si antes decíamos que el carácter expresivo del arte rupestre le permite representar imágenes vinculadas con realidades externas a él, podemos agregar ahora que es este mismo carácter el que abre también la posibilidad del repliegue del arte sobre sí mismo. De hecho, más allá de su significado, los motivos de manos positivas o negativas contienen de manera inherente una referencia a su propio productor ${ }^{10}$.

10 Para mencionar otro ejemplo, existe la posibilidad de que algunos de los motivos de personajes antropomorfos sean los propios productores de las imágenes representados mediante grabados o pinturas. 
Este doble carácter del arte rupestre dado por la materialidad de la representación se debe a la multiplicidad de niveles que, interrelacionados, le dan origen. Es precisamente su carácter expresivo el que hace del arte rupestre un medio de comunicación de contenidos sobre la realidad, y es su existencia material (incluyendo no solamente al arte como producto terminado sino a todas las relaciones sociales involucradas en su proceso de creación y uso) la que lo puede convertir en sujeto de su propia expresión.

Por último, es importante destacar que consideramos que este planteo no agota los niveles implicados en el complejo proceso que ha dado por resultado, en cada caso, la existencia del arte rupestre. Sin embargo, hemos acotado nuestra definición a los tres niveles mencionados por dos razones fundamentales. En primer lugar, nos hemos restringido a la definición de niveles que sean aplicables al análisis arqueológico del arte rupestre, dado que ése es nuestro objetivo principal. En segundo lugar, el presente es un trabajo de abordaje inicial al tema propuesto, razón por la cual no descartamos la posibilidad de ampliar la cantidad de niveles enunciados en futuras instancias de investigación.

\section{EL ARTE RUPESTRE COMO PRODUCTO SOCIAL: ESPECIFICIDAD HISTÓRICO-SOCIAL Y LA UNIDAD DE ANÁLISIS «ESTILO» (ALGUNAS VARIABLES PARA SU ESTUDIO)}

Puesto que hemos dicho que los niveles de análisis propuestos para el arte rupestre lo definen cualitativamente de manera amplia y general, y que luego, en un segundo momento, deben ser acotadas históricamente en tiempo y espacio, de acuerdo al contexto social del grupo productor / observador de las mismas, realizaremos en este acápite una breve síntesis de algunas variables que pueden resultar de interés en el abordaje de un grupo concreto de manifestaciones rupestres, variables que, a nuestro criterio, contribuyen a la definición de una unidad de análisis muy comúnmente utilizada: el estilo.

La discusión acerca del estilo en arqueología ha concentrado a su alrededor algunos fundamentales trabajos, tales como los de Conkey (1984, 1989) -estilo y estructuración de contenidos-, Earle (1990), Sackett (1990) -estilo y etnicidad, estilo e isocrestismo-, Shaafsma (1985) -espacio social y estilo- y Wiessner (1990) -estilo e información social-, entre otros. Estos trabajos demarcan la existencia de una problemática profunda y extendida acerca del estilo, problemática que, por supuesto, no pretendemos aproximarnos a resolver. Citaremos solamente entones los elementos que consideramos fundamentales en el 
momento de concebir al estilo y su operatividad en el campo del análisis del arte rupestre.

Sobre la definición de la unidad de análisis estilo, coincidimos con Shaafsma en que

«... el estudio de atributos formales con el objeto de identificar estilos de arte rupestre ha probado ser un medio útil de ordenar el arte rupestre... los estilos tienen asociaciones culturales y temporales especificas, y una definición espacial está también implícita. Las áreas de uniformidad estilistica constituyen esferas de interacción (Struever 1972) o redes panregionales de intercambio de información. Es más, el conocimiento de lo que constituye cualquier estilo dado facilita la identificación de sistemas visuales, que se relacionan con aspectos de significado y función. Así, la organización preliminar y el procedimiento descriptivo de aislamiento y definición de estilos no es visto como un fin en sí mismo, sino como un escalón con implicaciones para la investigación.» (Shaafsma 1985:245, la traducción es nuestra)

Más adelante, Shaafsma (ídem:246) cita a Sackett (1977:370) acerca de ciertas observaciones concernientes a la definición del concepto de estilo: a) el estilo concierne a una rnanera altamente específica de hacer algo y b) esta manera es siempre peculiar para un tiempo y un lugar específicos.

Por último, la autora (ibid.) cita a Forge (1977:30), quien define al estilo como «un set consistente de preferencias para ciertas formas y modos con un rango de variación permisible. Este rango es determinado por la sociedad, y los artistas de dicha sociedad en cualquier tiempo operan dentro de esos límites."

Si como primer paso hemos definido los niveles que caracterizan de manera amplia, general y abstracta al arte rupestre como producto social, consideramos que las siguientes variables permiten realizar el segundo paso de análisis (mencionado en acápites anteriores), acotando dichas características de manera que resulten útiles y relevantes para el abordaje de los casos concretos de estudio del arte rupestre, es decir, casos que se enmarcan en un momento histórico de un grupo social determinado.

Dichas variables son:

- especificidad temporal: margen temporal en el que un estilo de arte rupestre se desenvuelve, es decir, en el que las variables mencionadas a continuación se conjugan de una manera cualitativamente identificable

- especificidad espacial: uso característico que un estilo hace del espacio como sitio - propicio para ejecutar imágenes de arte rupestre y $/ 0$ para realizar actividades relacionadas con las mismas, tales como rituales, 
demarcaciones territoriales, etc.- y como soporte - propicio para emplazar todo tipo de representaciones, o cierto tipo de ellas, integrado a las mismas mediante el uso de su microtopografía, aparentemente ignorado, utilizado como delimitación entre paneles, etc.

- especificidad sociocultural: contexto de creación, vinculado con elementos materiales e ideales de la cultura productora en un momento determinado de su historia, que pueden conformar distintos referentes sobre los cuales se diseñan y construyen las representaciones

- especificidad morfológica: repertorio de motivos característicos de un estilo, básicamente su apariencia formal individual (intra motivo)

- especificidad tecnológica: modalidad de ejecución material de las imágenes de un estilo. Incluye las técnicas de realización de los motivos (formas de preparar el soporte, formas de utilizar los artefactos y de aplicar las pinturas para confeccionar los motivos sobre el soporte abarca tanto el trabajo físico de contacto entre artefacto y soporte como los gestos técnicos requeridos por cada movimiento) y los artefactos (para pintura y grabado) y elementos (para preparar el soporte, para componer la pintura) involucrados en dicho trabajo

- especificidad de contenidos o funcionalidad: vinculada básicamente con la comunicación de sensaciones por medio de la imagen, con el intercambio de información mediante la generación de significado por medio de sistemas visuales, y con las actividades rituales, cúlticas, etc. en las que el arte rupestre es uno de los elementos en juego. (Fiore 1992:12, 1993 a:36 y b)

Al conjunto de las variables mencionadas, agregamos en este trabajo la

- especificidad de composición: se trata de una variable relativa al diseño de la imagen, tanto en lo relativo al nivel intra-motivo (vinculándose con la variable especificidad morfológica), como al nivel inter-motivo. Tanto en uno como en otro nivel, involucra las pautas que subyacen al diseño plástico de la imagen, tanto de la imagen de un motivo aislado como de la imagen resultante de la interrelación de varios motivos en un panel de arte rupestre, o de la vinculación de varios paneles entre sí. Para definir esta variable nos hemos basado en los trabajos de Llamazares (1986 a, 1989); Leroi Gourhan (1984); Conkey (1989); Aschero y Podestá 1986; Aschero (1993) entre otros.

En todas estas variables se considera además, la existencia de un rango de variación en los valores que cada una de ellas pueda asumir en los distintos casos de análisis (Fiore 1992:17, 1993 a:93-96), constituyéndose de esta manera la casuística empírica que recuperamos como evidencia arqueológica. 
De esta manera, concebimos que el rango de variación expresa la posibilidad de la existencia de cambios cuantitativos en cada variable dentro del marco de un determinado estilo, cambios que conforman la variedad empírica de las imágenes rupestres, mientras que una determinada caracterización de las variables en su conjunto nos perrnite la definición del estilo como una entidad cualitativamente diferenciable, es decir, permite la diferenciación entre distintos estilos (Fiore 1993: $22,23)$.

Es la combinación de estas variables de análisis, y no el estudio aislado de una de ellas en particular, lo que nos posibilitará el abordaje concreto de las manifestaciones rupestres según los diversos niveles (composición plástica, contenidos ideológicos, proceso de trabajo) que caracterizan su existencia.

\section{EL ARTE RUPESTRE Y EL ESPACIO SOCIAL DE LA CREACIÓN}

Definidos ya los niveles que, a nuestro criterio, permiten abordar la existencia del arte como producto social, y las variables que posibilitan su acotamiento histórico-social mediante la aproximación estilística, queremos referirnos muy brevemente al contexto de producción del arte rupestre de manera más general.

De acuerdo con la perspectiva propuesta, nuestra concepción del arte como producto social contempla su vinculación con otros productos dentro del seno de una sociedad, que funciona como el contexto o el espacio social desde el cual se generan estos productos. "La creación es una actividad práctica en la cual el hombre produce algo nuevo a partir de una realidad preexistente» (Delgado 1988: 40).

Es desde esta perspectiva contextual que consideramos posible afirmar que el pensarniento y la creación nunca surgen en el vacío. Es imprescindible que ocurra la interacción entre el hombre y la realidad empírica de su contexto social para que aquel pueda realizar abstracciones no solamente acerca de lo que existe, sino también sobre lo que no existe en esa realidad. Imaginar lo que todavía no existe es uno de los factores que caracterizan a todo proceso de trabajo. A partir de la aceptación o de la negación de lo real, de la reparación del error, de la mirada hacia lo que falta, de la imaginación de lo que todavia no se ha producido, a partir de todos estos factores que nacen desde lo que ya existe, el hombre crea lo nuevo, lo que antes no existía. Es en el espacio de la falta donde se abre el lugar para la creación. 
Todo cambio, toda creación -como el arte rupestre, y también como su análisis-, es entonces producto de la interacción entre los hombres y su contexto social. Esta es precisamente la perspectiva que permite explicar la construcción de lo nuevo, la gestación del cambio, el surgimiento de "nuevas ideas" a partir de "viejos contextos". Toda producción social proviene, por lo tanto, de dicho contexto, pero no solamente reproduciéndolo, sino transformándolo desde los espacios generados por sus propias fallas (en el sentido de fisuras, contradicciones o rupturas con lo previo y desde lo previo), es decir, creando lo nuevo (Fiore 1993 a:27).

El arte rupestre no es solo una serie de reflexiones simbólicas sobre una realidad "exterior», es también una cornpleja realidad material en si misma, y, por la combinación de su condición material y su condición expresiva, tiene la posibilidad de reflexionar, incluso, sobre si rnismo. Toda producción social, incluyendo la artística, gesta algo nuevo desde un contexto previamente existente. En este sentido, toda producción, toda creación humana le agrega realidad a la realidad. A nuestro parecer, el arte rupestre no escapa a esta dinámica. Por el contrario, la confirma.

Buenos Aires, julio de 1994

\section{AGRADECIMIENTOS}

A Myriam Tarragó por la calidez y entusiasmo de sus comentarios durante la dirección de mi Tesis, que estimularon la realización de este trabajo.

A Myrian Álvarez y María L. Varela por la lectura crítica del manuscrito, y por sus enriquecedores comentarios.

Por supuesto, ninguna de ellas es responsable de las consideraciones aquí vertidas.

\section{BLBLIOGRAFIA}

Álvarez, M. y D. Fiore.

1993. La arqueología como ciencia social: un enfoque teórico-epistemológico. Boletín de Antropología Americana. 27. IPGH. México, pp. 21-38..

1994. "Análisis de los procesos de producción del arte rupestre y de los artefactos liticos en el Paraje Paso de los Molles, área Pilcaniyeu, sudoeste de Rio Negro: conclusiones que convergen". XI Congreso Nacional de Arqueología Argentina. 23 al 29 de Mayo. San Rafael. Mendoza. (En prensa).

ARUTINOV, S.A.

1977-1978. The many levels of the problem of the genesis or art. Soviet anthropology and archaeology. Vol. XVI. N ${ }^{\circ} 3-4$. 
AsCHERO, C.

1988. Pinturas rupestres, actividades y recursos naturales, un encuadre arqueológico. Arqueología Contemporánea Argentina. Yacobaccio editor. Ed. Búsqueda.

1993. ¿A dónde van esos guanacos?. Segundas Jornadas de Arqueología de la Patagonia. Puerto Madryn.

Aschero, C. y M.M. Podesta.

1986. El arte rupestre en asentamientos precerámicos de la Puna Argentina. Runa. Vol XVI. Buenos Aires.

BAHN, C., Y J. VERTUT.

1988. Images of the ice age. Windward.

BATE, L.F.

1970. Primeras investigaciones sobre el arte rupestre de la Patagonia chilena. Anales del Instituto de la Patagonia. Vol. I. N ${ }^{\circ} 1$. Punta Arenas.

1981. Relación general entre teoría y método en arqueología. Boletín de Antropología Americana. $\mathrm{N}^{\circ}$ 4. Instituto Panamericano de Geografia e Historia. México.

Boschin, M.T. y A.M. Llamazares.

1992. Arte rupestre de la Patagonia. Las imágenes de la continuidad. Ciencia Hoy. Vol. 3. $\mathbf{N}^{\circ}$ 17. Buenos Aires.

Bruner, J.S. 1988. Desarrollo cognitivo v educación. J. Palacios cornpilador. Ediciones Morata, S.A. Madrid.

Casamiquela, RM.

1968. Novedades interpretativas con relación a nuevos yacimientos con grabados rupestres del norte de la Patagonia. Actas y Memorias. XXXVII Congreso Internacional de Americanistas. (1966). Vol III. Buenos Aires.

1981. El arte rupestre de la Patagonia. Ed. Siringa.

CONKEY, M.

1984. To find ourselves: art and social geography of prehistoric hunter-gatheres. Past and Present in Hunter Gatherer Studies. Ed. M. Shire. Academic Press. New York.

1989. The structural analysis of Paleolithic art. Archaeological thought in America. C.C. Lamberg Karlovsky editor. Cambridge University Press. New York.

DELGADO, L.

1988. Los cornponentes estéticos de la práctica social. Notas para el estudio del arte prehispánico. Boletin de Antropologia Americana $N^{\circ} 18$. Instituto Panamericano de Geografia e Historia. México.

EARLE, T.

1990. Style and iconography as legitimation in complex chiefdoms. The uses of style in archaeology. Ed. by M. Conkey and C. Hastort Cambridge University Press. Cambridge.

FIORE, D.

1992. La distribución espacial del estilo “pisadas" en el área Pilcaniyeu. Presentado en el seminario: El arte rupestre y mobiliar del NOA en su contexto arqueológico. Facultad de Filosofia y Letras. UBA. Buenos Aires. MS.

1993 a. La producción del arte rupestre en el área Pilcaniyeu, provincia de Río Negro. Tesis de Licenciatura. Universidad de Buenos Aires. Facultad de Filosofia y Letras. Buenos Aires. MS.

1993 b. El proceso de producción de arte rupestre en el área Pilcaniyeu, provincia de Rio Negro. Cuademos del Museo Etnográfico. Universidad de Buenos Aires. Facutlad de Filosofia y Letras. Buenos Aires. En prensa.

Fossati, A.; L. JafFe; M. Simoes dE ABREU

1990. Rupestrian Archaeology. Techniques and Terminology. A methodological Approach: Petroglyphs. Ricerche Archeologiche. Vol 1. Tomo I. First English Edition. Edizioni della Cooperativa Archeologica Le Orme dell Uomo. Val Camonica. Brescia. Italia.

García Canclini, N.

1986. La producción simbólica. Teoría y método en sociología del arte. Ed. Siglo XXI.

Godelier, M.

1976. Antropologia v economía. Anagrama. Barcelona.

GONZALEZ, A R

1974. Arte. estructura e ideología. Análisis de figuras duales y anatrópicas del Noroeste Argentino. Nueva Visión. Buenos Aires.

1977. Arte precolombino de la Argentina. Filmediciones Valero. 
Gradin, C.

1978. Algunos aspectos del análisis de las manifestaciones rupestres. Revista del Museo Provincial. Tomo 1. Arqueología. Neuquén.

1988. Caracterización de las tendencias estilisticas del arte rupestre de la Patagonia (Provincias de Rio Negro, Chubut y Santa Cruz, República Argentina). Nuevos estudios del arte rupestre argentino. C.J. Gradin y J. Shobinger. Contribuciones al estudio del arte rupestre sudamericano. $\mathbf{N}^{\circ} 2$. Sociedad de Investigación del Arte Rupestre de Bolivia. La Paz.

Gradin, C. y J. SHOBInger

1985. Arte rupestre de la Argentina. Cazadores de la Patagonia y Agricultores Andinos. Ediciones Encuentro. Madrid.

JOCHIN, M.

1985. Arte rupestre paleolitico desde una perspectiva ecologica. Hunter Gatherers Economy in Prehistory. Ed. Bailey. Cambridge University Press. Cambridge.

Krapovickas, P.

1961. Noticia sobre el arte rupestre de Yavi prov. de Jujuy, república Argentina. Anales de Etnografia v Arqueología. Tomo 16.

LAMING EMPERAINE, A.

1962. La Signification de l'art rupestre paléolithique. Editions A. \& J. Picard \& $C^{\circ}$. Paris.

LeROI GOURHAN, A.

1976. Sur les aspects socio-économiques de l'art paléolithique. L'autre et l'ailleurs; Hommages a Roger Bastide, s. 1. Berger-Levrault.

1984. Arte y Grafismo en la Europa Prehistorica. Ed. Istmo. Madrid.

LEVINE, M.H.

1957. Prehistoric art and ideology. American Anthropology.

LEWIS WILLIAMS, J.D. Y T.A. DOWSON

1988. The signs of all times. Current Anthropology. Vol 29. $\mathrm{N}^{\circ} 2$.

Llamazares, A.M.

1982. El arte rupestre del Abrigo de Pilcaniyeu, provincia de Rio Negro. Relaciones de la Sociedad Argentina de Antropologia. T. XIV. N 1. N. S. 1980. Buenos Aires.

1986 a. A semiotic approach in rock-art analysis. Trabajo presentado en el Symposium "Material Culture and Symbolic Expression". Precirculados: Archaeological 'objectivity' in interpretation. Vol I. World Archaeological Congress. $1^{\circ}$ al $7^{\circ}$ de Septiembre. University of Southampton. Southampton.

1986 b. Hacia una definición de semiosis. Cuadernos del Instituto Nacional de Antropología. 11. Buenos Aires.

1989. A semiotic approach in rock-art analysis. The meaning of things. lan Hodder Ed. Londres. LLANOS, A.

1986. Introducción a la dialéctica. Ed. Rescate. Buenos Aires.

MARSHAC, A.

1989. Methodology in the analysis and interpretation of upper Palaeolithic image: theory versus contextual analysis. Rock art research. Volume 6. Number 1.

MENGHIN, O.F.A.

1957. Estitos del arte rupestre de Patagonia. Acta Praehistórica I. Buenos Aires.

NúÑEZ ATENCIO, L.

1976. Geoglifos y tráfico de caravanas en el desierto chileno. Tomo de Homenaje al R.P. G. Le Paige.

PODESTA, M.

1986-87. Arte rupestre en asentamientos de cazadores recolectores y agroalfareros de la puna sur argentina: Antofagasta de la Sierra, Catamarca. Relaciones de la Sociedad Argentina de Antropología. Tomo XVII.

SACKETT, J.

1990. Style and etnicity in archaeology: the case for isochrestism. The uses of style in archaeology. Ed. by M. Conkey and C. Hastorf. Cambridge University Press. Cambridge.

SHAAFSMa, P.

1985. Form, content and function: theory and method in North America rock art studies. Advances in Archaelogical Method and Theory. Vol 8. Compit. M. Schiffer. Academic Press. New York. 
SHOBINGER, J.

1956. El arte rupestre de ta provincia de Neuquén. Anales de Arqueología y Etnología. Tomo XII. Universidad Nacional de Cuyo. Facultad de Fitosofía y Letras. Mendoza. Argentina.

StOLIAR, A.D.

1977-1978. On the genesis of depictive activity and its role in the formation of conciousness (Toward a formulation of the problem). Soviet anthropology and archaeology. Vol. XVI. $\mathbf{N}^{\circ}$ 3-4.

VARGas ARENAS, $I$.

1986. Arqueologia, ciencia y sociedad. Boletín de Antropología Americana. $N^{\circ} 14$. Instituto Panamericano de Geografía e Historia. México.

WIESSNER, $P$.

1990. Is there a unity to style? The uses of style in archaeology. Ed. by M. Conkey and C. Hastorf. Cambridge University Press. Cambridge.

YaCOBACCIÓN, H. D.

1979. Arte rupestre y tráfico de caravanas en la puna de Jujuy: modelo e hipótesis. Jornadas de Arqueología del Noroeste Argentino. Buenos Aires. 